\title{
Perceptions on Online Reputation Management in Tourism Industry (The Case of a Romanian Hotel)
}

\author{
Alexandru Capatina \\ Dunarea de Jos University of Galati \\ Romania \\ George Cristian Schin \\ Dunarea de Jos University of Galati \\ Romania
}

Received: Feb. 15, 2017

doi:10.5296/jmr.v9i2.10754
Accepted: March 10, $2017 \quad$ Published: April 1, 2017

URL: https://doi.org/10.5296/jmr.v9i2.10754

\begin{abstract}
Online reputation management plays a significant role in tourism industry, as tourists are more and more interested to express their opinions about their experiences with their circles of friends. The rise of pure players such as Booking.com, TripAdvisor, Travelocity, as well as the connection of hotels' clients on social mention websites make the hotel management teams aware of the necessity to build a customer feedback observatory, especially in online environment.

This research explores the effects of the positive, respectively negative reviews on the image of GRAND ORIENT hotel of Brăila, which have a strong impact on this brands' success in online social networks. Factors with greatest influence in what concerns choosing the services offered by the hotel, the degree of interaction between the respondents and different sites which promotes reviews of hotel services and the methods through which this hotel might stimulate its customers to post reviews are also addressed by this study.

The main contribution of the study reflects that online reputation management has a significant positive effect on hotel branding strategies, as the customers are empowered to share their opinions regarding their experiences on a wide variety of social-media networks.
\end{abstract}

Keywords: online reputation, hotel management, tourism industry, social networks

JEL Code: M15, L83, Z33 


\section{Theoretical background}

The tourism industry has been always recognized as an information intensive domain (Inversini et al., 2010). Tourism services are characterized by being heterogeneous (Sirakaya $\&$ Woodside, 2005), being also related to customer experiences.

Many research studies in the hospitality industry have recognized that influence by online reviews has a big impact on bookings. This effect is magnified for e-WOM (word-of-mouth), where the impact of online dissemination of opinion is more far-reaching (Calveras and Orfila, 2009; Smyth et al., 2010).

The widespread use of online hotel reviews proves to be an opportunity rather than a threat to managers in the hotel industry (Litvin, Goldsmith, \& Pan, 2008); in this context, the exposure to an online hotel review as well as its assessment improve the average probability for potential customers to consider booking a room in the reviewed hotel (Vermeulen $\&$ Seegers, 2009).

The customers' intentions to book and trust in the target hotel are higher following exposure to positively online reviews than negatively online reviews (Ye et al., 2011).Understanding the impact of online reviews on hotel performance is extremely important for hotels that rely their strategy on customer online reviews to disseminate information about their experienced services (Xie et al., 2014).

A study focused on the impact of star rating and customer rating on hotel room sales and price strategy has shown that higher customer ratings result in higher prices of the hotel and the prices of high star hotels are more sensitive to online customer ratings (Ogut \& Onur Taş, 2012).

The sentiment analysis (positive or negative) of online reviews and ratings has a significant impact on potential consumers and their purchase decisions related to hotel bookings. The results of a recent research (Schuckert et al., 2015) reveal a positive correlation between hotel purchasing intention and the sentiment associated of reviews.

\section{Research objectives}

The research on the reputation of Grand Hotel Orient Braila in the online environment had developed in the period 05.05.2016 - 30.05.2016, the questionnaire being administered to a representative specimen of 158 potential or actual customers of the hotel. As way of approaching the respondents, we choose to place the questionnaire on hotel's Facebook page, fact that allowed an efficient interaction with the respondents, all monitoring the posts of the hotel's representatives on this modern communication channel.

\section{The objectives of the research:}

- Identification of the degree in which the customers' reviews influences the decisions of purchase of other customers;

- Identification of the influence factors in what concerns the selection of the services offered by GRAND ORIENT hotel ofBrăila; 


\section{Macrothink}

- The analysis of the effects of the positive, respectively negative reviews on the image of GRAND ORIENT hotel ofBrăila.

\section{Discussions on results}

The first question from the questionnaire (filter question) dealt with identification of the number of respondents who have been using the services offered by Grand Hotel Orient Braila (Figure no. 3.1)up to present.

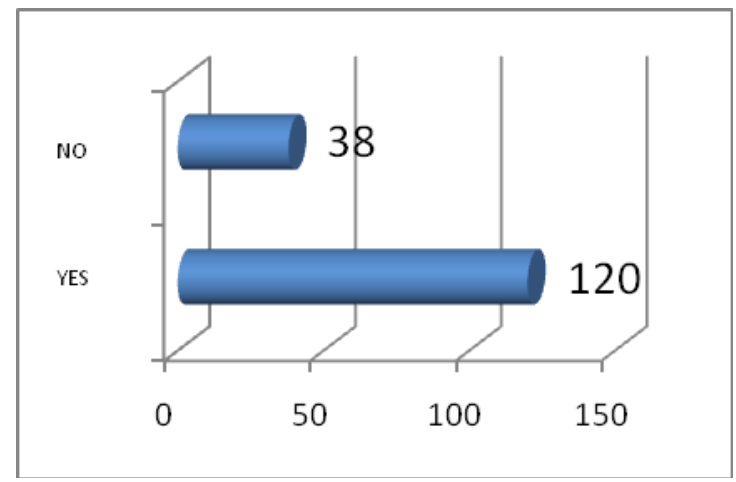

Figure 3.1. Segmentation of the respondents' specimen

As it can be observed, out of 158 respondents, 120 have been customers of the hotel up to present; only these 120 customers will go through the following questions of the questionnaire, being the only ones capable to express pertinent opinions in connection to the reputation of Grand Hotel Orient Braila in the online environment. The actual number of the customers of the hotel analysed is very high as reported to the total number of the respondents, a normal thing if we regard it from the point of view that all respondents follow-up the hotel's Facebook page.

The second question has as purpose determining the perception of those 120 customers of the hotel on the quantitative and qualitative level of the information presented on the website of Grand Orient hotel of Brăila, as well as on its Facebook page. The recorded results demonstrate a positive appreciation of the online communication managed by the representatives of Grand Hotel Orient Braila (cumulated weighting of High and Very High levels being $88 \%$ - Figure no. 3.2).

The website of Grand Hotel Orient Braila and its Facebook page as well, are created by experts, being based on the experience with customers. Their content reflects updated information on rooms, fees and services which differentiate it from competition. 


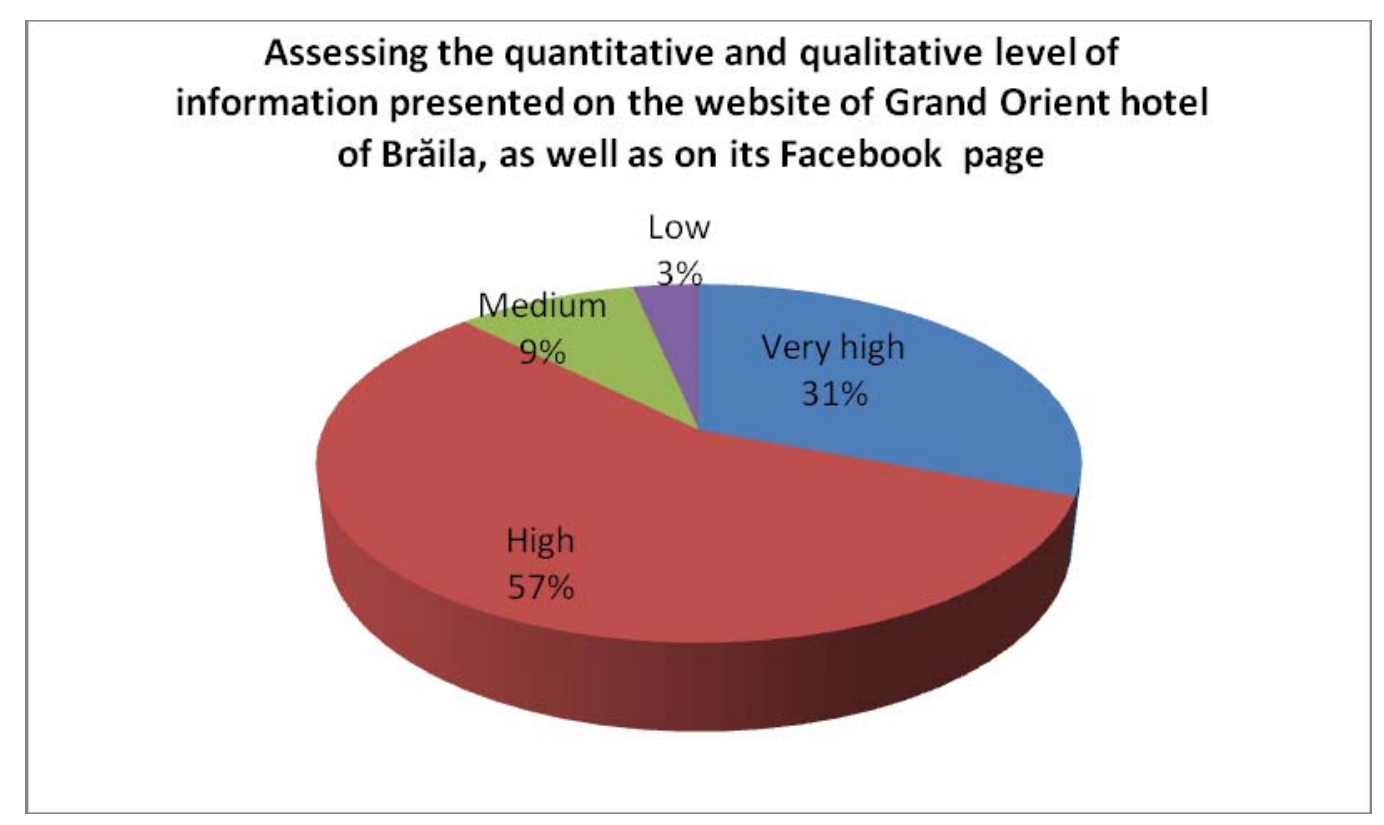

Figure 3.2. Analysis of the online communication managed by the representatives of Grand

Orient hotel of Brăila

The third question had as purpose the ranking of factors that had the highest influence in what concerns choosing the services offered by GRAND ORIENT hotel of Brăila. The results obtained following to processing the answers demonstrates a clear detachment in the hierarchy of the reviews posted by other customers on specialised sites (booking.com, tripadvisor.com, etc.) (43\%), as compared to the other predefined answers (Hotel's Facebook page $-20 \%$, friends recommendations $-14 \%$, influence of the representatives of a tourism agency $-13 \%$ or the web page of the hotel analysed - 11\%) (Figure no. 3.3).

E-tourism is based on the delivery of promises to the customers, the latter being extremely sensitive to the reviews of other customers posted on specialised sites, the most relevant being TripAdvisor and Booking.com. As the grades associated to the reviews are higher, the probability for a potential customer to choose the services of the hotel is higher.

Friends' recommendations do not have the same effect like in the case of other services or in the case of purchases of large consumption or extended usage goods. Neither the online communication of the hotel, nor the discussions with the representatives of the tourism agencies favour the decision of purchasing some hotel services like in the case of the reviews of other customers. Right on this niche the global businesses have developed, the most eloquent example being TripAdvisor. 


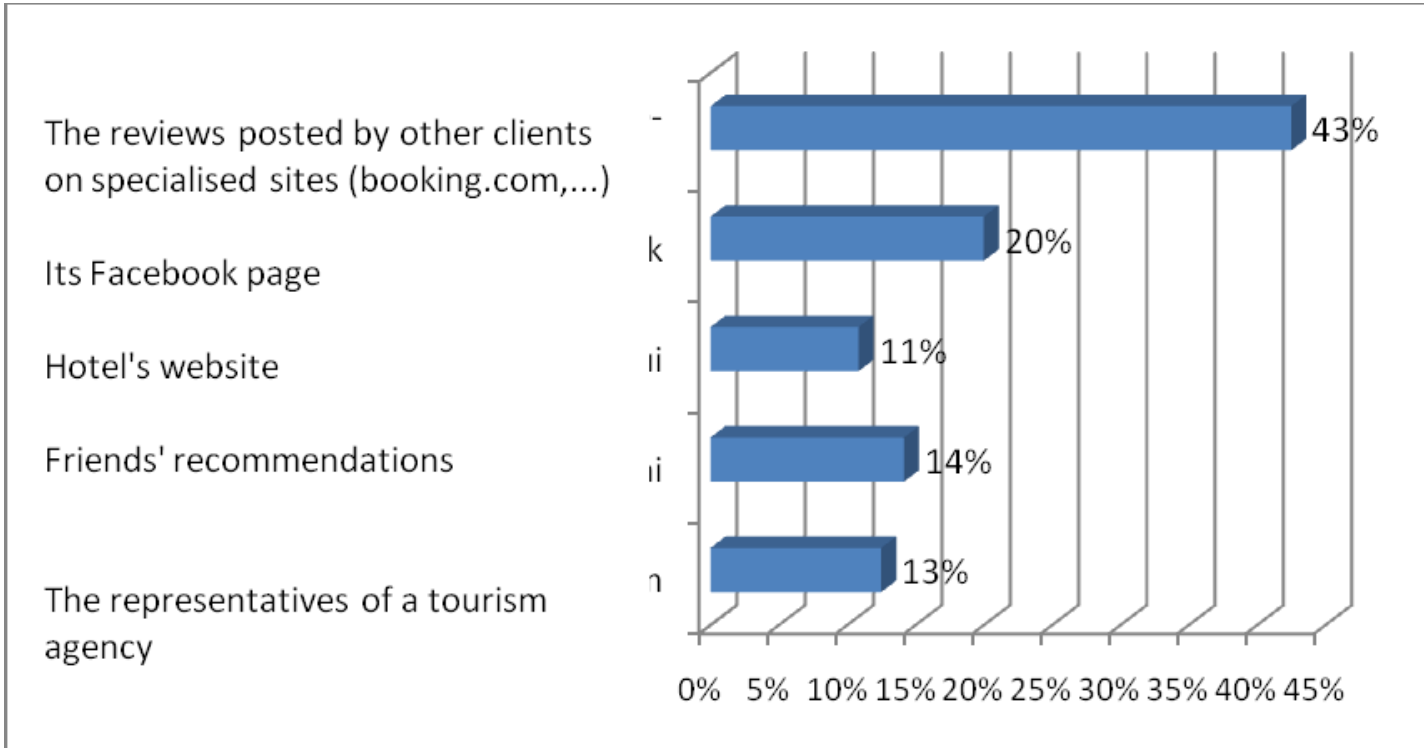

Figure 3.3. Ranking of factors with greatest influence in what concerns choosing the services offered by the hotel

Through this fourth question, we had as purpose analysing the degree in which the reviews of other customers of Grand Hotel Orient Braila are relevant in choosing its services. As it can be observed from the previous analyses of the ratings and comments associated to the hotel in different websites of e-Tourism, but especially from the answers to this question, the role of the reviews is decisive in choosing the services of Grand Hotel Orient Braila (over $90 \%$ from the respondents have selected the predefined answers "To a very large extent" or "To a large extent"- Figure no. 3.4).

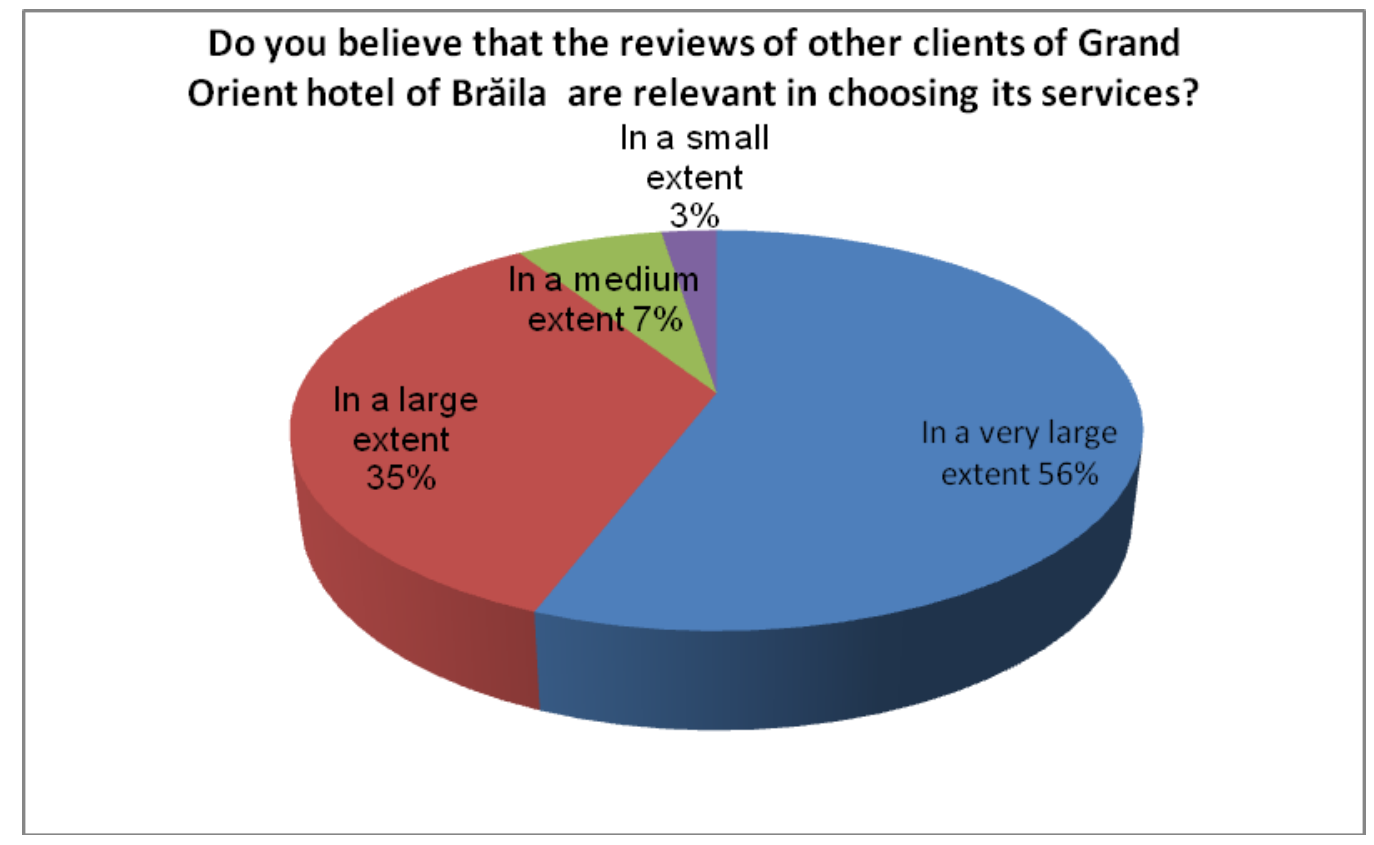

Figure 3.4. Role of reviews in choosing a Grand Orient hotel of Brăila 
On the other hand, the analysis of the reviews done by the hotel's specialists in Marketing allows them to track customers' sources of unhappiness, which can generate a crisis of image, but especially to concentrate their campaigns of drawing in and building customers loyalty on positive reviews, which are in majority in the case of Grand Orient hotel ofBrăila.

I consider thus that the customers' reviews stay at the basis of the management strategies of the relations with customers (Customer Relationship Management), applied with success by the hotel which I manage.

The fifth question does not refer strictly to the services of Grand Hotel Orient Braila or to their perception from the perspective of the reputation in the online environment; it proposes to identify the degree of interaction between the respondents and different sites which promote reviews of hotel services.

A quite significant percentage (28\%) from the respondents asserts that they did not make any reviews on the speciality sites, while the simple majority $(51 \%)$ made between one and five reviews. The percentage of those who did more than five reviews is comparable with the one associated to the respondents who did not made any review (Figure no. 3.5).

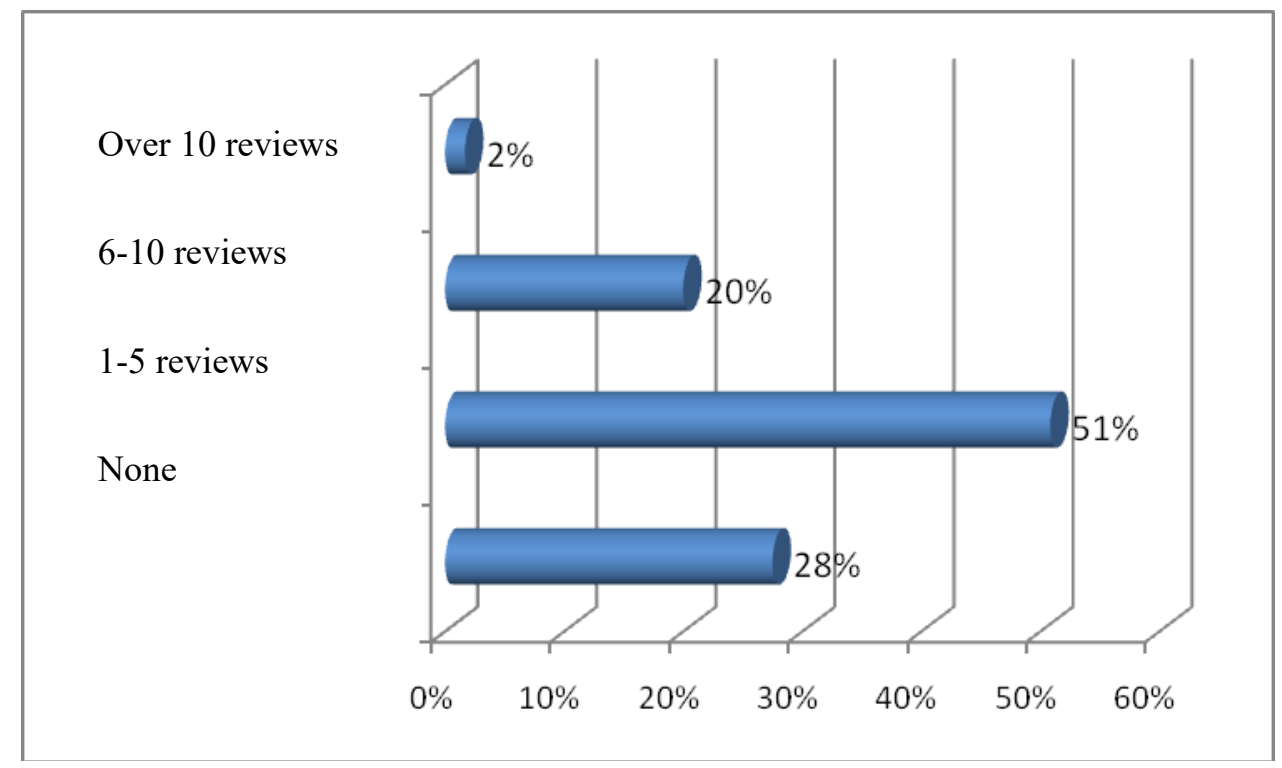

Figure 3.5. Degree of interaction between the respondents and different sites which promotes reviews of hotel services

All hotels which affiliate successfully to e-Tourism approach must find solutions of stimulating the customers in order to post comments or to rate the hotel whose services are promoted online. A question which will be analysed next proposes such solutions which can be efficient marketing instruments, with a role of increasing the notoriety of a hotel brand.

The sixth question has as purpose the ranking of the online hotel booking and reviews posting sites in which the respondents have the greatest trust.

As it can be observed in Figure no. 3.6, most participants to the research achieved based on the questionnaire proposed have the greatest trust in Booking.com (39\%), the world leader of 
online hotel bookings, with more than 6.3 million weekly bookings on its website and with a version dedicated in Romanian language. TripAdvisor (27\%) is placed on the second position - the most important online community dedicated to travels, with over 340 million unique visitors per month, 350 million reviews which cover over 6.5 million accommodation establishments, restaurants and tourist attractions from the entire world; www.tourneo.ro (18\%) website is a site which presents the accommodation establishments from Romania through which online bookings can be done. Google Reviews (13\%) and Trivago.com (3\%) are less used by respondents in searching for reviews.

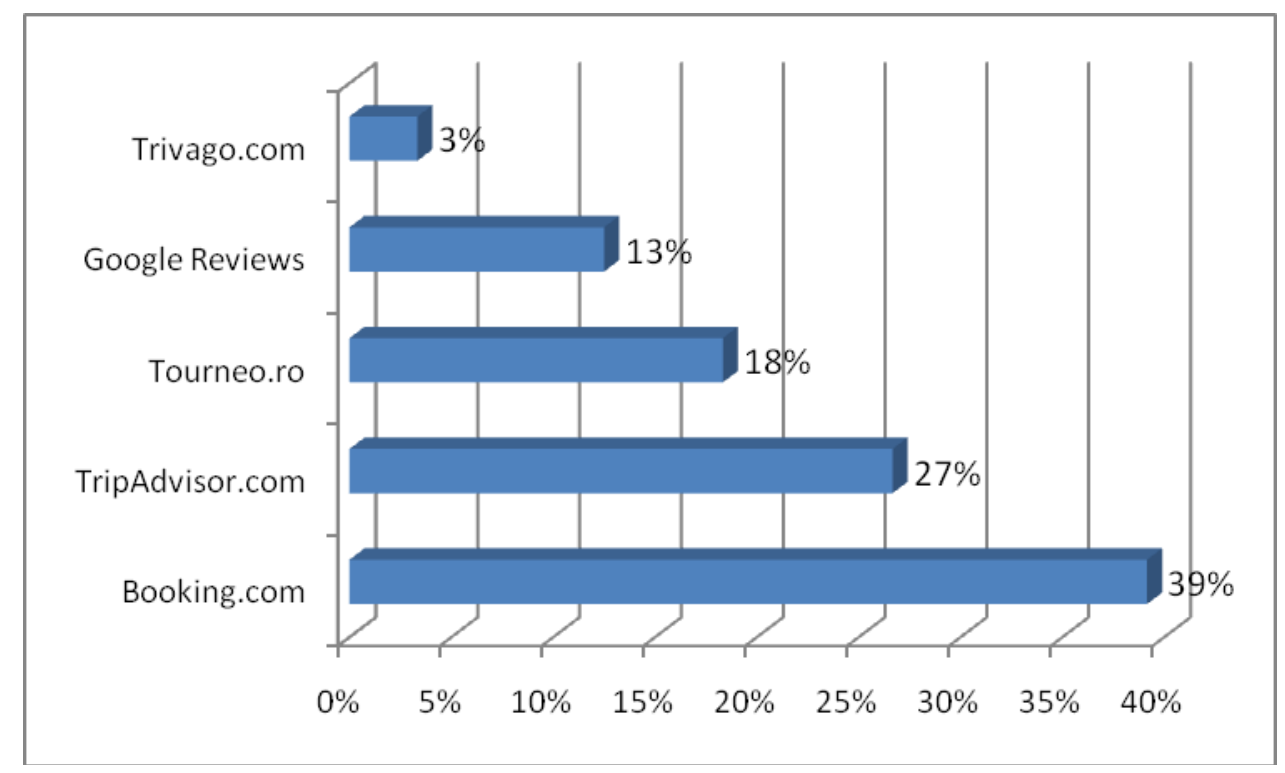

Figure 3.6. Respondents trust in sites specialised in online hotel booking and reviews posting

Of course, there are other sites with which Grand Hotel Orient Braila has concluded contracts of representation in the online environment, but they are not introduced in this question.

The seventh question has as priority objective determining the perception of the respondents on the effects of displaying the positive reviews in case of GRAND ORIENT hotel of Brăila. Most respondents $(60 \%)$ consider that the positive reviews and comments have lead to an increase of the trust of other potential customers, while the increase of the hotel's brand notoriety $(18 \%)$, respectively increasing the conversion rates of the visitors of online booking sites into customers of the hotel (16\%) are appreciated as being secondary rank effects. According to the opinion of the same respondents, displaying positive reviews has had a quite insignificant impact on building the loyalty of customers (6\%) - Figure no. 3.7. 


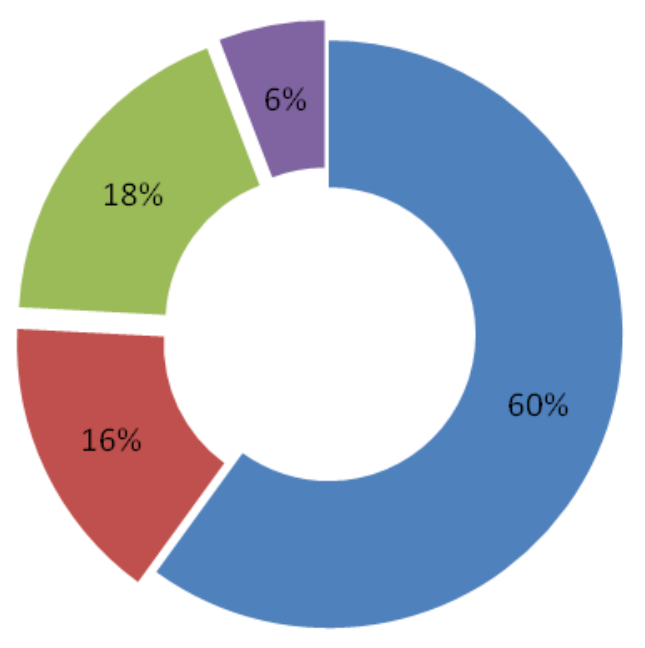

Higher trust of other potential customers

Increasing the conversion rates of the visitors of the online booking sites into customers of the hotel Increasing the notoriety of the hotel brand

Building the loyalty of the customers

Figure 3.7. The effects of displaying positive reviews in case of GRAND ORIENT hotel of Brăila

The positive comments and impressions in connection to the touristic services represent the main arguments had in view by the managers in positioning and especially in differentiating the hotel services which they manage. The hotel reputation management in online environment is built based on these positive perceptions of the customers.

The experiences of some companies which got even to bankruptcy due to customers' complaints expressed in negative reviews which can be extremely easily distributed through social networks, constitute the argument of formulating the eight question which dealt with the impact of displaying negative reviews in case of GRAND ORIENT hotel of Brăila.

Fortunately, Grand Hotel Orient Braila did not receive any negative review on either site up to this moment, but this thing cannot block in time the occurrence of some unhappy customers which can express such sentiments.

The respondents consider that in case of the unwanted occurrence of some negative reviews associated to GRAND ORIENT hotel of Brăila, the effects would translate in customers' losses $(34 \%)$, in cancellation of partnership contracts $(28 \%)$, in the erosion of the hotel image $(26 \%)$ and in decreasing the hotel income (13\%) - Figure no. 3.8. 


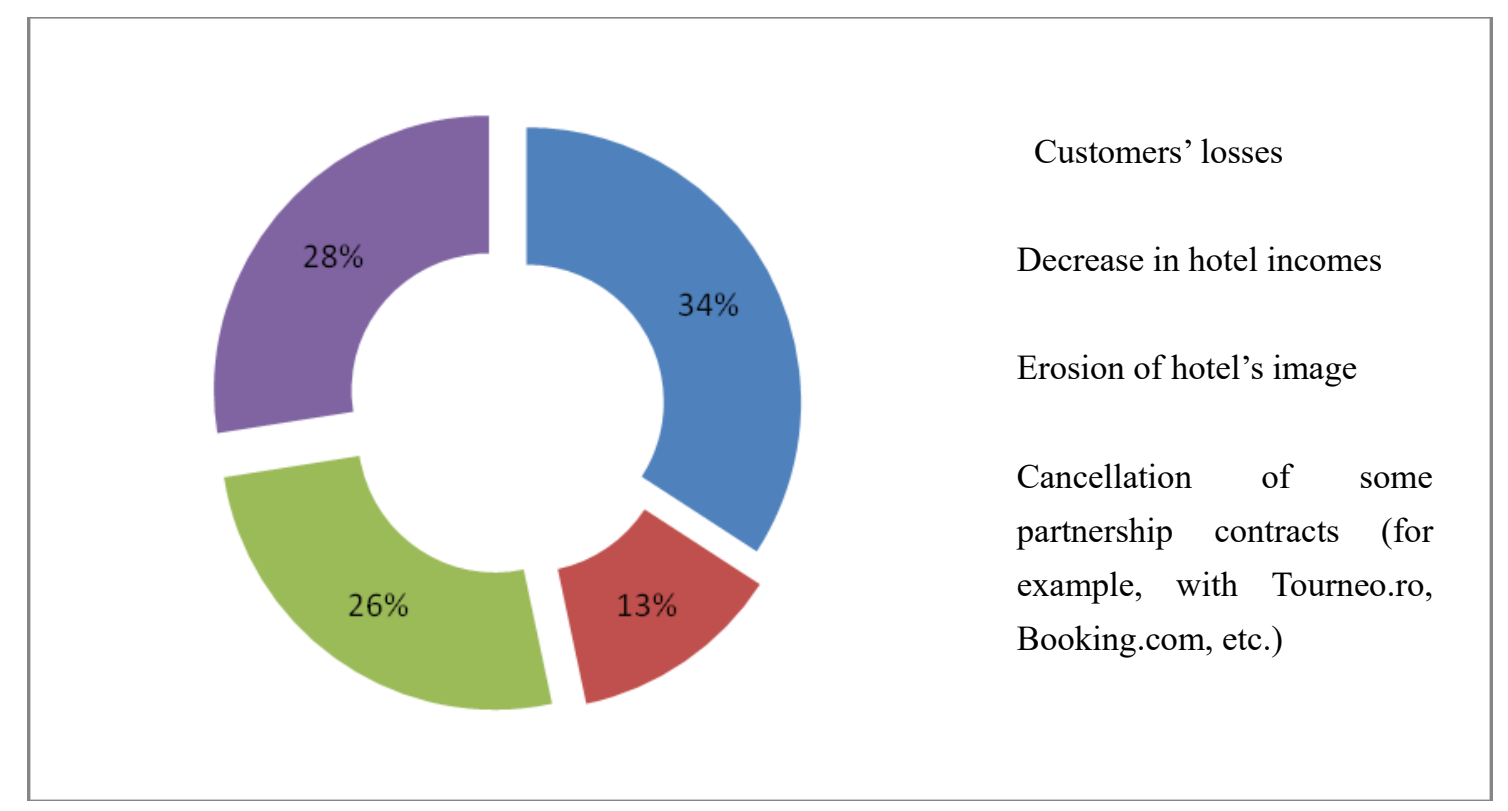

Figure 3.8. The effects of displaying the negative reviews in case of Grand Hotel Orient

Braila

The ninth question proposes to identify if the respondents monitor closely the posting of Grand Hotel Orient Braila on its Facebook page. Most of the respondents (70\%) monitor the messages posted by the administrator of the hotel's Facebook page, while $24 \%$ assert that they will try to connect in the immediate future to the hotel's Facebook page; the $6 \%$ who do not monitor the posts can be converted into frequent visitors of the Facebook page, through a personalised page, which can explain the advantages of receiving updates (Figure no. 3.9).

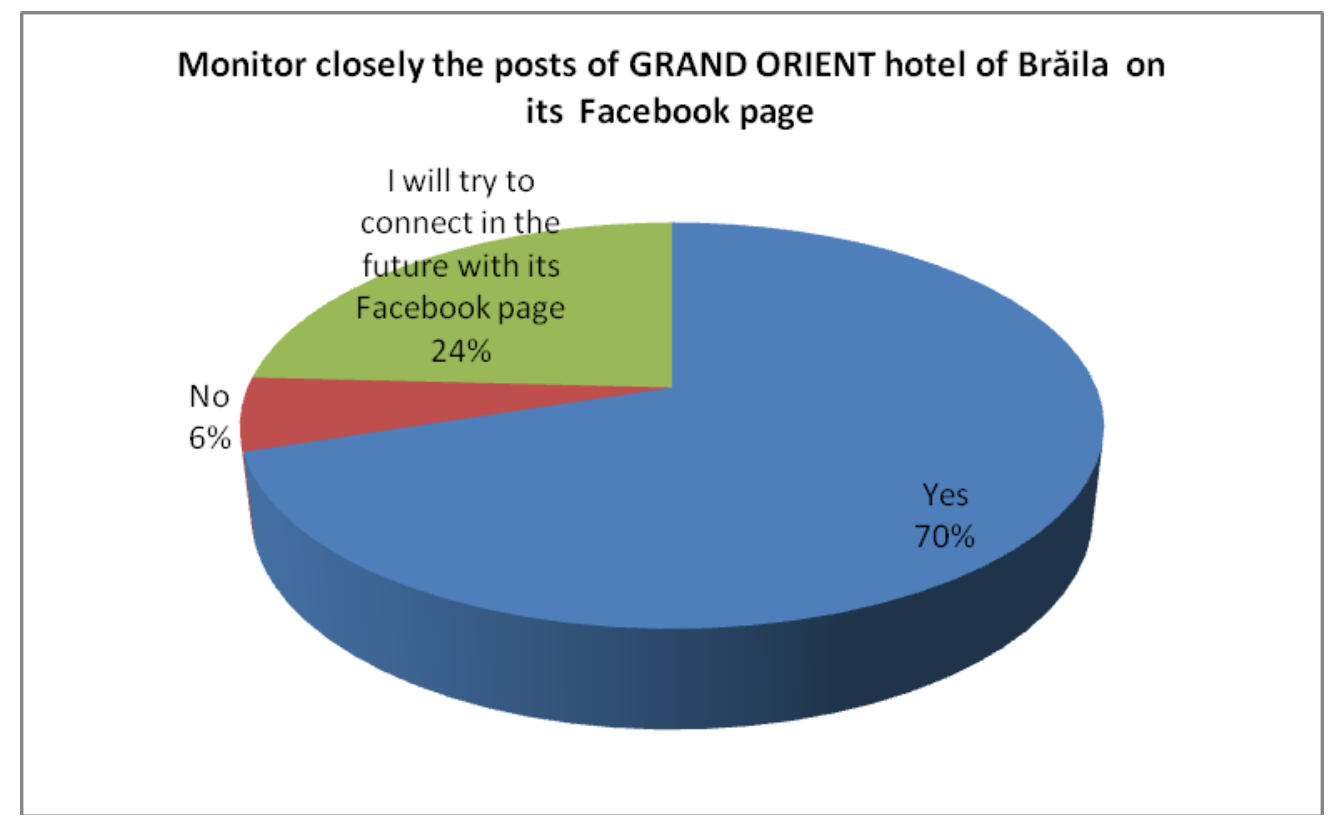

Figure 3.9. The degree of monitoring the posts of Grand Hotel Orient Braila on its Facebook page

From e-Tourism perspective, Grand Hotel Orient Braila must adopt an integrated 
communication of the content it desires to send to its target audience. The Facebook page plays an essential role in the online communication policy; due to this reason, the updates are programmed at short time intervals, in order to maintain the attention focused on the offers of the hotel.

The tenth question monitors the opinions of the respondents on some methods through which Grand Hotel Orient Braila could stimulate its customers to post reviews. This practice is often met in the business promoted in online environment.

Out of the methods proposed by the management team of GRAND ORIENT hotel of Brăila, the respondents appreciate the most being offered the possibility to register in a contest with prizes (44\%), followed by discounts to the following packs of hotel services purchased $(41 \%)$. In a smaller measure it is appreciated the facility to issue reviews on its Facebook page $(15 \%)$, not existing in this situation incentives of financial type - Figure no. 3.10.

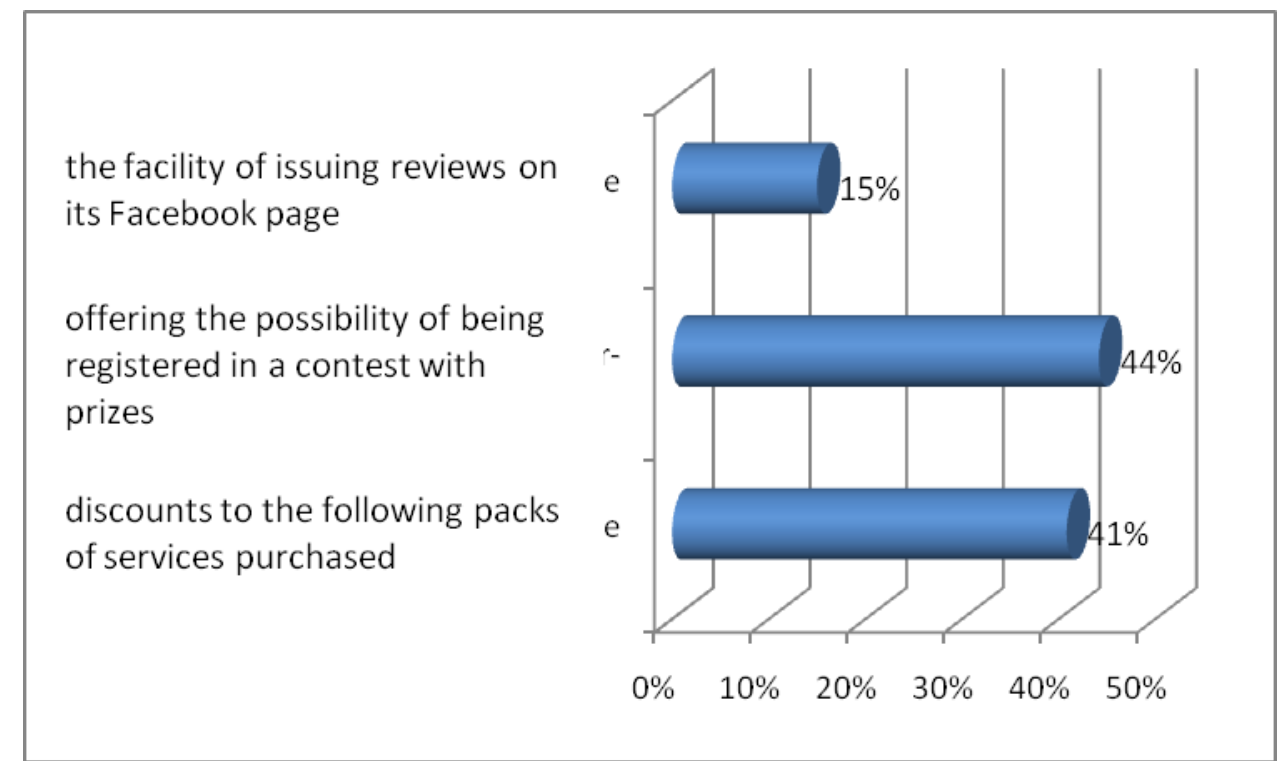

Figure 3.10. Methods through which Grand Hotel Orient Braila might stimulate its customers to post reviews

E-tourism appreciates any initiative from hotels' part in what concerns stimulating the interest of their customers to post comments. Many sites that intermediate between hotels and customers have been involving in projects of improving reviews, this leading automatically to increasing the traffic and implicitly the conversions onto their sites.

The degree of satisfaction felt by the respondents in what concerns the online way of communication of Grand Hotel Orient Braila represented the subject of the eleventh question of the questionnaire.

We observe a predominance of the cumulated answers which indicate the fact that the respondents are very satisfied, respectively satisfied (91\%) by the actual ways of the online communication of GRAND ORIENT hotel of Brăila, while only $9 \%$ from the respondents are satisfied in an medium measure (Figure no. 3.11). Not even a respondent did manifest the discontent in connection to the services of GRAND ORIENT hotel of Brăila, fact that 


\section{Macrothink}

resonates with the existence of only one positive review associated with this hotel.

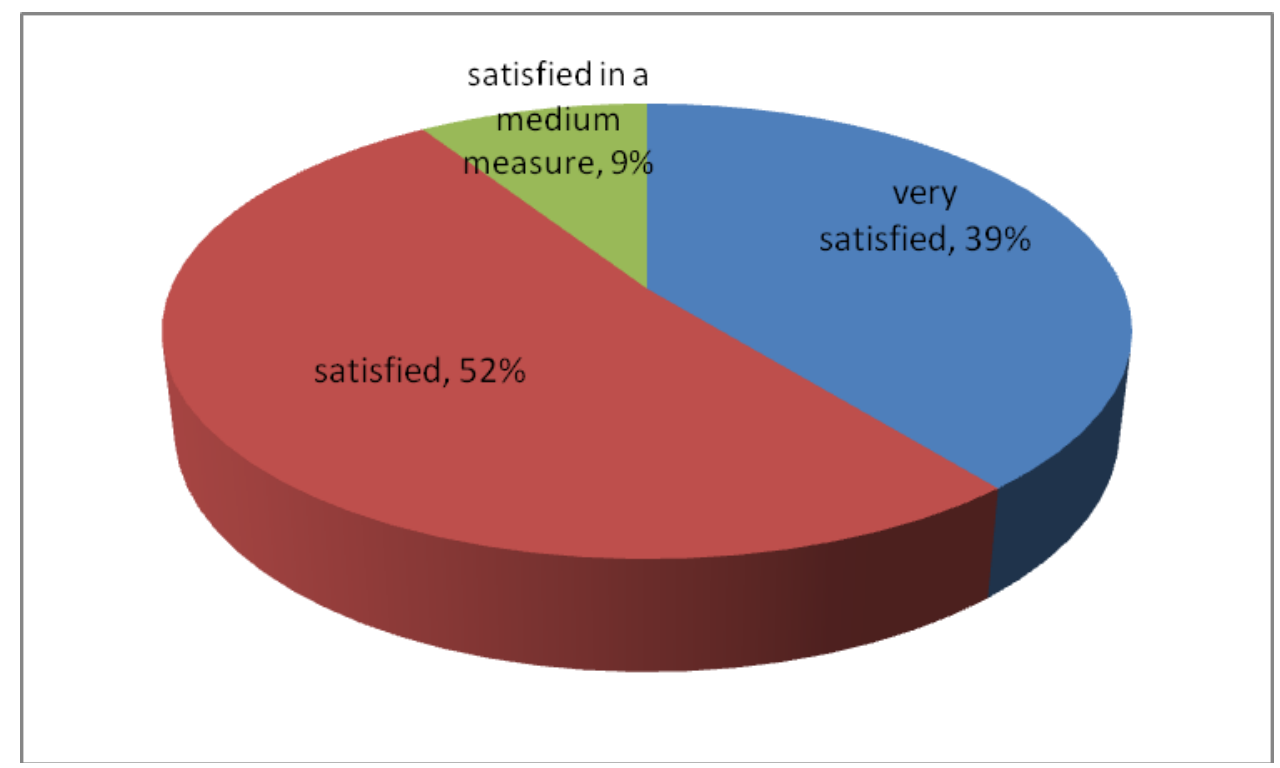

Figure 3.11. Degree of satisfaction in what concerns the way of online communication of

Grand Hotel Orient Braila

The management of customers' satisfaction in e-tourism is efficient only in case the interactive communication with the customers, through methods based on Internet, proves its efficiency, so that the key performance indicators will be reached.

The twelfth question proposes to the respondents to grant a grade, on a scale from 1 (min) to 5 (max), to the way in which Grand Hotel Orient Braila manages its reputation in online environment.

I considered pertinent to highlight through rating formulae (from 1 to 5 stars) - Figure no. 3.12 the assessment grid to this question. The answers obtained denote that $60 \%$ from the respondents give maximum score to the hotel, while $34 \%$ give 4 points out of 5 . Only $6 \%$ give 3 points out of 5 , while none of the respondents did tick off a rating of 1 , respectively of 2 stars. 


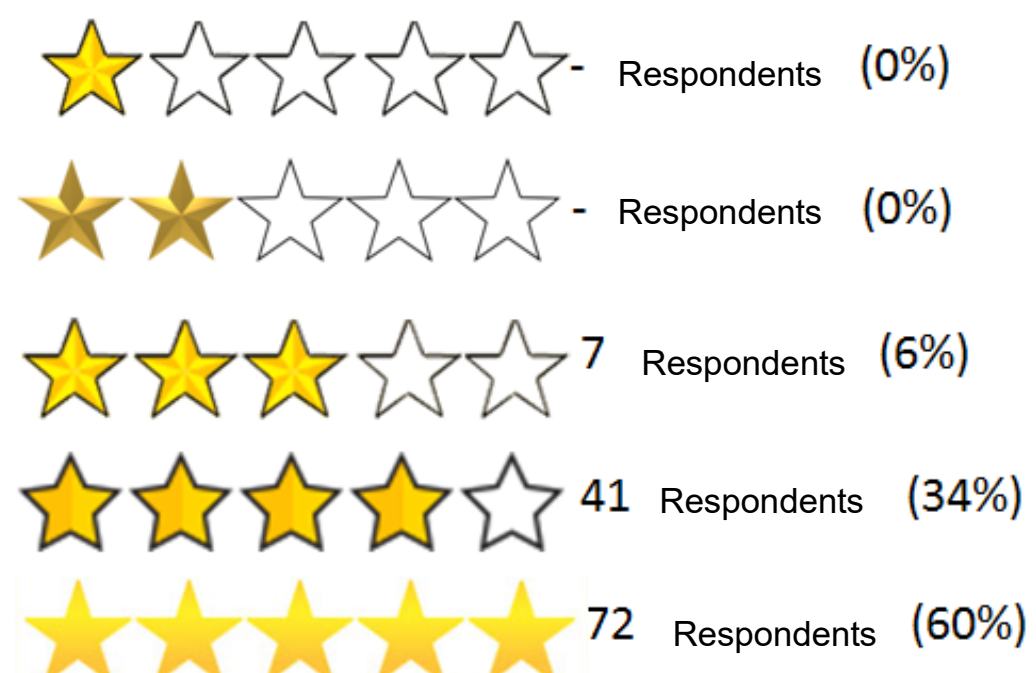

Figure 3.12. The rating of the respondents in assessing the way in which Grand Hotel Orient Braila manages its reputation in online environment

These results do not only confirm the previous results of the research, but also the realities from the online environment in what concerns the perception of the excellent way in which Grand Hotel Orient Braila has been managing its reputation in the online environment.

\section{Conclusions and future research agenda}

Following the research results, the implementation of techniques for creating online identity by displaying positive reviews on sites such as Booking.com, TripAdvisor contribute to the growth of online reputation hotels. Although the Grand Hotel Orient Braila has earned a favourable reputation in the online environment, the management team must be aware of the benefits that it have not used all online identity management tools to attract and keep customers.

The positive perceptions expressed by reviews of customers Grand Hotel Orient Braila is a result of applying the techniques of creating online identity. The online reputation campaigns managed by Grand Hotel Orient Braila management team successfully fulfilled the role of influencing other potential customers.

The management team of Grand Hotel Orient Braila must be connected therefore to the newest management practices of the reputation in the online environment, many consultancy companies being able to come to its support.

Future research will explore Grand Hotel Orient Braila clients' commitment to share valuable reviews and other forms of content that generates shares, with a high propensity to receive increased organic reach.

Acknowledgements: Authors thank to the CEO of Grand Hotel Orient Braila - Mr. Florin Radu, for his valuable support on conducting this research. 


\section{Macrothink}

Journal of Management Research

ISSN 1941-899X

2017, Vol. 9, No. 2

\section{References}

Calveras, A., \& Orfila, F. (2009). Intermediaries and Quality Uncertainty: Evidence from the Hotel Industry. In Second Conference of The International Association for Tourism Economics, http://ssrn.com/abstract $=1009647$

Inversini, A., Marchiori, E., Dedekind, C., \& Cantoni, L. (2010). Applying a conceptual framework to analyze online reputation of tourism destinations. Information and communication technologies in tourism, 321-332. https://doi.org/10.1007/978-3-211-99407-8_27

Litvin, S. W., Goldsmith, R. E., \& Pan, B. (2008). Electronic word-of-mouth in hospitality and tourism management. Tourism Management, 29(3), 458-468. https://doi.org/10.1016/j.tourman.2007.05.011

Ogut, H., \& Onur Taş, B. K. (2012). The influence of internet customer reviews on the online sales and prices in hotel industry. The Service Industries Journal, 32(2), 197-214. https://doi.org/10.1080/02642069.2010.529436

Schuckert, M., Liu, X., \& Law, R. (2015). Hospitality and tourism online reviews: Recent trends and future directions. Journal of Travel \& Tourism Marketing, 32(5), 608-621. https://doi.org/10.1080/10548408.2014.933154

Sirakaya, E., \& Woodside, A. G. (2005). Building and testing theories of decision making by travellers. Tourism management, 26(6), 815-832. https://doi.org/10.1016/j.tourman.2004.05.004

Smyth, P. C. B., Wu, G., \& Greene, D. (2010). Does TripAdvisor makes hotels better?. Technical Report, (08).

Vermeulen, I. E., \& Seegers, D. (2009). Tried and tested: The impact of online hotel reviews on consumer consideration. Tourism management, 30(1), 123-127. https://doi.org/10.1016/j.tourman.2008.04.008

Xie, K. L., Zhang, Z., \& Zhang, Z. (2014). The business value of online consumer reviews and management response to hotel performance. International Journal of Hospitality Management, 43, 1-12. https://doi.org/10.1016/j.ijhm.2014.07.007

Ye, Q., Law, R., Gu, B., \& Chen, W. (2011). The influence of user-generated content on traveler behavior: An empirical investigation on the effects of e-word-of-mouth to hotel online bookings. Computers in Human Behavior, 27(2), 634-639. https://doi.org/10.1016/j.chb.2010.04.014 


\section{Appendix}

Structure of the sample

\begin{tabular}{|c|c|c|}
\hline Gender & Number of respondents & Percentage \\
\hline Male & 68 & $57 \%$ \\
\hline Female & 52 & $43 \%$ \\
\hline Total & 120 & $100 \%$ \\
\hline
\end{tabular}

\begin{tabular}{|c|c|c|}
\hline Age group & Number of respondents & Percentage \\
\hline Less than 25 years & 11 & $9 \%$ \\
\hline $\begin{array}{c}\text { Between 25 and 40 } \\
\text { years old }\end{array}$ & 42 & $35 \%$ \\
\hline $\begin{array}{c}\text { Between 40 and 55 } \\
\text { years old }\end{array}$ & 45 & $38 \%$ \\
\hline Over 55 years old & 22 & $18 \%$ \\
\hline Total & 120 & $100 \%$ \\
\hline
\end{tabular}

\begin{tabular}{|c|c|c|}
\hline $\begin{array}{l}\text { Monthly income of } \\
\text { the respondents }\end{array}$ & Number of respondents & Percentage \\
\hline Less than 1,000 lei & - & - \\
\hline $\begin{array}{c}\text { Between 1,000 and } \\
2,000 \text { lei }\end{array}$ & - & - \\
\hline Between 2,000 and & 42 & $35 \%$ \\
\hline 3,000 lei & 78 & $65 \%$ \\
\hline Over 3,000 lei & 120 & $100 \%$ \\
\hline Total & \multicolumn{2}{|c|}{} \\
\hline
\end{tabular}




\begin{tabular}{|l|c|c|}
\hline $\begin{array}{l}\text { Level of studies of } \\
\text { the respondents }\end{array}$ & Number of respondents & Percentage \\
\hline Primary studies & - & - \\
\hline High school studies & 26 & $22 \%$ \\
\hline University studies & 75 & $64 \%$ \\
\hline Postgraduate studies & 29 & $24 \%$ \\
\hline Total & 120 & $100 \%$ \\
\hline
\end{tabular}

